\begin{tabular}{|c|l|}
\hline Title & Mesoscale Simulation of Influence of Frost Damage on Mechanical Properties of Concrete \\
\hline Author(s) & Ueda, Tamon; Hasan, Muttaqin; Nagai, Kohei; Sato, Y asuhiko; W ang, Licheng \\
\hline Citation & $\begin{array}{l}\text { Journal of Materials in Civil Engineering, 21(6), 244:252 } \\
\text { https:/doi.org/L0.1061/AA SCE)0899-1561(2009)21:6(244) }\end{array}$ \\
\hline Issue Date & 2009-06 \\
\hline Doc URL & http://hdl.handle.net/2115/39349 \\
\hline Type & article (author version) \\
\hline File Information & 21-6_p244 252.pdf \\
\hline
\end{tabular}

Instructions for use 


\title{
Meso-scale Simulation of Influence of Frost Damage on Mechanical Properties of Concrete
}

\author{
Tamon Ueda; Muttaqin Hasan²; Kohei Nagai ${ }^{3}$; Yasuhiko Sato ${ }^{4}$; Licheng Wang ${ }^{5}$
}

Abstract: Meso-scale constitutive models of frost-damaged concrete are developed in this study through numerical simulation using a two-dimensional Rigid Body Spring Model (RBSM). The aim of the simulation is to predict the macro behavior of frost-damaged concrete subjected to mechanical loading. The models also clarify the difference in failure behavior of concrete with and without frost damage. Zero strength elements and the concept of meso-scale plastic tensile strain are introduced into the normal RBSM springs to consider the experimentally observed cracking and plastic deformation caused by frost damage. The difference in the effect of frost damage on compression and tension behavior as found in the experiments is clearly predicted.

Finally, analysis of notched beam subjected to bending after different degrees of frost damage is

1 Dr. Eng., Professor, Division of Built Environment, Graduate School of Engineering, Hokkaido University, Kita-ku, Kita 13, Nishi 8, Sapporo, Japan 060-8628, e-mail: ueda @eng.hokudai.ac.jp

2 PhD., Lecturer, Department of Civil Engineering, Faculty of Engineering, Syiah Kuala University, Darussalam, Banda Aceh 23111, Indonesia

${ }^{3}$ Dr. Eng., Assistant Professor, Division of Civil Engineering, University of Tokyo, Bunkyo-ku, Hongo 7-3-1, Tokyo, Japan 113-8656

4 Dr. Eng., Associate Professor, Division of Built Environment, Graduate School of Engineering, Hokkaido University, Kita-ku, Kita 13, Nishi 8, Sapporo, Japan 060-8628

${ }^{5}$ PhD., Associate Professor, State Key Laboratory of Coastal and Offshore Engineering, Dalian University of Technology, Dalian 116024, China 
carried out. The resulting load-deflection curves agree well with those obtained in experiments. These good correlations confirm the applicability of the meso-scale model for predicting the macro behavior of frost-damaged concrete.

CE Database subject headings: Meso-scale Constitutive Model; Frost Damage; Rigid Body Spring Model (RBSM); Meso-scale Plastic Tensile Strain; Zero Strength Element (ZSE).

\section{Introduction}

The study of concrete at the meso-scale is useful for the precise evaluation of its characteristics, which are affected by the material characteristics of its components, such as mortar and aggregate, and their interfaces. Furthermore, deterioration in the material characteristics of concrete that has been damaged as a result of environmental action will, in future, be predicted through analysis at this scale (Wittmann 2004). Frost damage is one type of environmental deterioration that occurs in cold regions. Typical frost damage consists of surface scaling and internal micro-cracking caused by expansion of the materials (i.e. mortar).

In recent years, there have been many studies on the mesoscopic modeling of concrete and concrete structures subjected to mechanical loading (Nagai et al. 2004; 2005; Stroeven and Stroeven 2001; Asai et al. 2003; Bazant et al. 2004). At the meso-scale, in which concrete is considered a composite material with three-phases (aggregates, mortar and interfacial transition 
zones between them), Nagai et al. (2004; 2005) succeeded in simulating the failure mechanism and failure modes of mortar and concrete specimens using both two- and three-dimensional methods. By incorporating accurate meso-scale morphology, realized using an image-based geometry modeling technique, into a lattice-type numerical model, Asai et al. (2003) simulated the cracking behavior of concrete induced by meso-scale heterogeneities. Bazant et al. (2004) introduced a Confine-Shear Lattice Model (CSL model), in which the concrete meso-structure is simulated by a lattice connecting particles that represent the aggregate pieces. However, no meso-scale analysis of damaged concrete has previously been conducted. In this paper, analysis at the meso-scale of frost-damaged concrete subjected to mechanical loading is presented. The constitutive models used in the analysis are developed based on the plasticity and fracturing concepts. Moreover, the difference in failure behavior of concrete with and without frost damage is discussed.

The analysis is carried out using a two-dimensional Rigid Body Spring Model (RBSM). RBSM is a discrete numerical analysis method first developed by Kawai (1977). The analytical model is divided into polyhedron elements whose boundaries are interconnected by two springs, called normal and shear springs, as shown in Fig. 1. Each element has two translational and one rotational degree of freedom at the center of gravity. A mesh arrangement of random geometry using a Voronoi diagram is used (Okabe at al. 2000) and a geometric computational program 
developed by Sugihara (1998) is applied.

Normal and shear elastic moduli are calculated by assuming a plane stress condition as follows (Nagai et al. 2004).

$$
\begin{aligned}
& k_{n}=\frac{E}{1-v^{2}} \\
& k_{s}=\frac{E}{1+v}
\end{aligned}
$$

where $k_{n}$ and $k_{s}=$ elastic modulus of the normal and shear spring; and $E$ and $v=$ elastic modulus and Poisson's ratio of the element. Material constants $(E, v)$ at the aggregate-mortar interface are calculated as in Fig. 2.

\section{Summary and modification of Nagai's models}

The models developed in this study are mostly based on those developed by Nagai et al. (2004) for non-damaged concrete with some modifications. In those models, the authors assumed that no fracturing occurs in compression and that the tensile strength of the mortar and its interfaces has a truncated normal distribution with the following probability density function:

$$
\begin{aligned}
& f\left(f_{t}\right)=\frac{1}{s \sqrt{2 \pi}} \exp \left\{-\frac{\left(f_{t}-\bar{\mu}\right)^{2}}{2 s^{2}}\right\} \\
& s=-0.2 \bar{\mu}+1.5
\end{aligned}
$$

where $f_{t}=$ element tensile strength, and for $f_{\mathrm{t}}<0$, set $f_{\mathrm{t}}=0 ; \bar{\mu}=$ average value of element tensile strength; and $s=$ standard deviation. The same distribution was assumed for the normal and shear 
stiffness.

The elastic constitutive relationship for a normal spring was adopted. Fracturing takes place between mortar or interface elements when the normal spring reaches its tensile strength; subsequently the normal stress falls linearly with increasing crack width. However, in compression, the spring always behaves elastically. It was also assumed that the maximum crack width at which tensile stress can be transferred is constant, even for springs with different strengths and initial stiffness, as shown in Fig. 3a. This assumption is modified in the present study, such that this maximum crack width has a distribution depending on the tensile strength and corresponding crack width, as shown in Fig. 3b. The slope for tension softening is assumed to be unique, with values chosen in such a way that the average tensile strength at the average initial stiffness would resolve to a stress-free maximum crack width equal to $0.03 \mathrm{~mm}$, which is the value assumed in Nagai et al. (2004). The reason of this change in the assumption for the meso-scale model is the experimental fact that the stress-free maximum crack width in tension softening in macro-scale increases slightly with the maximum tensile stress in macro-scale (JSCE 2005b). The normal spring assumed by Nagai et al. behaves elastically based on elastic-fracturing concept, so a linear unloading and reloading path that passes through the origin was adopted, as shown in Fig. 4a. However, this simple assumption may not be correct because of the experimental fact that there are remaining strains under both compression and tension in 
macro-scale. In this study, the normal spring is assumed to have elasto-plastic and fracture behavior. As a result, the unloading and reloading path does not pass through the origin, but has some plasticity. The plasticity increases and the stiffness decreases as the strain at the unloading point increases. To model this phenomenon, a linear unloading-reloading path that follows the envelope stress-strain curve in compression at a strain of $\varepsilon_{p a}$ is adopted, as shown in Fig. 4b.

For shear spring, Nagai et al. proposed an elasto-plastic model. Shear stress is proportional to shear strain until it reaches a maximum value $\left(\tau_{\max }\right)$ and then remains constant at $\tau_{\max }$ as shear strain rises further. The $\tau_{\max }$ criterion for mortar was developed by the authors, while the one for interfaces was based on the failure criterion suggested by Taylor and Broms (1964) and Kosaka et al. (1975) as follows:

For mortar: $\tau_{\max }= \pm\left(f_{t}+0.11 f_{t}^{3}\left(-\sigma+f_{t}\right)^{0.6}\right)$

For interfaces: $\tau_{\max }= \pm(-\sigma \tan \phi+c)$

where $\sigma=$ normal stress; and $\phi$ and $c=$ constants. When fracture occurs in the normal spring, the maximum shear stress also falls according to the increase in crack width opening.

As for the aggregate, it is assumed that aggregate elements behave only elastically without fracturing (Nagai et al. 2004).

\section{Meso-scale constitutive models of frost-damaged concrete}


Frost action causes internal micro-cracking which leads to expansion of the concrete. This expansion can be represented by the remaining plastic tensile strain of concrete that has been subjected to frost action after any mechanical loading has been removed. At the meso-scale, the remaining tensile strain due to frost action can be simulated by elongation of the normal spring. In this paper, this remaining plastic tensile strain of the normal spring is referred to as "meso-scale plastic tensile strain" ( $\left.\varepsilon_{p f}\right)$. Due to the random nature of micro-cracking caused by frost action (Jacobsen et al. 1995; Yang et al. 2006), these meso-scale plastic tensile strains are distributed randomly among the normal springs. In this study, a truncated normal distribution of meso-scale plastic tensile strain, as described by the following equation (see Fig. 5), is assumed:

$$
f\left(\varepsilon_{p f}\right)=\frac{1}{s_{1} \sqrt{2 \pi}} \exp \left\{\frac{\left(\varepsilon_{p f}-\bar{\mu}_{1}\right)^{2}}{2 s_{1}^{2}}\right\}
$$

where $\varepsilon_{p f}=$ distributed plastic tensile strain of normal spring, and for $\varepsilon_{p f}<0$, set $\varepsilon_{p f}=0 ; \bar{\mu}_{1}=$ average plastic tensile strain of normal spring, taken as the experimentally measured value at a certain degree of frost damage for each specimen; and $s_{1}=$ standard deviation, $s_{1}=\delta \cdot \bar{\mu}_{1}$, where $\delta$ is the variation coefficient of plastic tensile strain of the normal spring, with the same value as the tensile strength of mortar and interfaces in Eq. (2).

The constitutive relationships for normal springs having a meso-scale plastic tensile strain smaller than the strain $\varepsilon_{\max }$ at the maximum crack width for stress transfer are shown in Fig. 6a. 
A linear stress-strain relationship with a stiffness of $k_{l}\left(<k_{n}\right)$ for tensile stresses less than $f_{t a}$ (on the envelope of the stress-strain relationship for undamaged concrete) is assumed. Once the stress reaches $f_{t a}$, it falls linearly with increasing crack width until reaching zero at the maximum crack width. Accordingly, the maximum shear stress also decreases according to Eqs. (3) and (4). In compression, a bilinear stress-strain relationship is assumed. The stiffness is $k_{l}$ until reaching the envelope of the stress-strain relationship for undamaged concrete at $\varepsilon_{p a}$. Once the envelope curve is reached, microcracks caused by frost damage are assumed fully closed due to compression and stiffness is fully recovered. To facilitate the calculation of normal spring stress, the starting point for every step of mechanical loading is treated as the origin and the relationship can then be written as follows (see Fig. 6b):

$$
\begin{aligned}
& \sigma_{n}=k_{1} \varepsilon \text { for } \varepsilon \geq-\left(\varepsilon_{p f}+\varepsilon_{p a}\right) \\
& \sigma_{n}=k_{n}\left(\varepsilon+\varepsilon_{p f}\right) \text { for } \varepsilon<-\left(\varepsilon_{p f}+\varepsilon_{p a}\right)
\end{aligned}
$$

where $\sigma_{n}=$ normal spring stress; $k_{n}=$ elastic modulus of undamaged normal spring; $k_{1}=$ elastic modulus of damaged normal spring; $\varepsilon=$ normal strain; $\varepsilon_{p f}=$ meso-scale plastic tensile strain; $\varepsilon_{p a}$ is a material constant with a value of 0.0004 in this study; and $f_{t a}=$ normal stress as defined in Fig. 6 and written as follows: 


$$
\begin{aligned}
& f_{t a}=k_{1} \varepsilon_{t a} \\
& \varepsilon_{t a}=\frac{\left(\varepsilon_{\max }-\varepsilon_{p f}\right)\left(\varepsilon_{p a}+\varepsilon_{p f}\right)}{\varepsilon_{p a}\left(\varepsilon_{\max }-\varepsilon_{o}\right)+\varepsilon_{o}\left(\varepsilon_{p a}+\varepsilon_{p f}\right)} \varepsilon_{o} \\
& \varepsilon_{o}=\frac{f_{t}}{k_{n}}
\end{aligned}
$$

where $\varepsilon_{\max }=$ strain corresponding to maximum crack width beyond which no stress is transferred (see Fig. 4 and Fig. 6). The stiffness of a damaged normal spring can be written as follows:

$$
k_{1}=\frac{\varepsilon_{p a}}{\varepsilon_{p a}+\varepsilon_{p f}} k_{n}
$$

If the meso-scale plastic tensile strain exceeds the strain corresponding to the maximum crack width, the normal spring cannot carry the normal stress any more. Besides, the shear spring is unable to bear the shear stress, either. Elements that are no longer able to carry stress are called zero strength elements (ZSE). ZSEs represent elements that have become totally fractured due to frost damage. With increasing meso-scale plastic tensile strain, more elements reach this total fracture state, increasing the number of ZSEs as meso-scale plastic tensile strain rises. This means that the ratio of the number of ZSEs to the total element count can be described as a function of meso-scale plastic tensile strain, as follows (see ZSE in Fig.5):

$$
\frac{n_{Z S E}}{N}=36.725 \varepsilon_{p f}<1.0
$$

where $n_{Z S E}$ is the number of ZSEs and $N$ is the total number of elements. The constant in Eq. (9) is chosen in such a way that the relationship between calculated reduction in strength and 
stiffness for both tension and compression agree well with experimental results.

\section{Meso-scale analysis of frost-damaged concrete}

The program developed by Nagai et al. (2004) was used in the analysis and the meso-scale constitutive models for frost-damaged concrete developed in this study were implemented. The stiffness matrix was constructed based on the principal of virtual work (Kawai and Takeuchi 1990). The modified Newton-Raphson method was used as the convergence algorithm. In the convergence process, displacements canceling the unbalanced forces of elements are added to the elements. The displacements are calculated using the stiffness matrix. Convergence of the model is judged when the ratio of the summed squares of unbalanced forces to the summed squares of applied forces falls below $10^{-5}$. Displacement of the loading boundary was controlled.

The input material properties are shown in Table 1 . In fact, some of the properties in Table 1 are not independent but affect each other. The method proposed by Nagai et al. (2004), based on experiments conducted by Hsu and Slate (1963), Taylor and Broms (1964), Kosaka et al. (1975) and Yoshimoto et al. (1983), was used for the relationship between the material properties. The material parameters in Table 1 were chosen such that the compressive strength of undamaged concrete was near to the experimental value of 49.8 MPa (Hasan et al. 2004).

\section{Compression analysis}


Compression analysis was conducted on five specimens with different levels of average plastic tensile strain assumed caused by different degrees of frost damage, matching those measured in a previous experimental study (Hasan et al. 2004). The plastic tensile strains given to each specimen are distributed from zero to a value twice the average plastic tensile strain, or 0,340 , 700, 1240 and $1783 \mu$ for the five specimens, respectively. The models analyzed have dimensions $100 \mathrm{~mm}$ x $200 \mathrm{~mm}$. Circular aggregate particles were distributed randomly through the analyzed models. The aggregate size distribution follows the JSCE Standard Specification for Concrete Structures (JSCE 2005a) with a maximum diameter of $20 \mathrm{~mm}$. The volume of aggregate was $40 \%$ of the total volume of the model. The analyzed model was divided into 2200 polyhedron elements as shown in Fig. 7.

Stress-strain curves of the analytical models are compared with experimental data from Hasan's experimental study in Fig. 8. On the ascending branch, there is comparatively good correlation between analytical and experimental results. However, due to the feature of the testing machine the descending branch could not be recorded. Therefore, in the present paper, the comparison is made only for the ascending branch, focusing on the reduction of strength and stiffness. Further research is needed to experimentally study the softening property of concrete subjected to frost damage. The experimental finding that the stiffness of frost-damaged concrete gradually recovers with rising stress at rather low stress levels is simulated well. A comparison 
between the degradation of compressive strength and elastic modulus of frost-damage concrete obtained in analysis and experiment is shown in Fig. 9. Good agreement is apparent.

Figures 10 and 11 compare the crack patterns of five specimens analyzed in this study up to the maximum stress level and to $80 \%$ of the maximum stress level in the softening branch. At the maximum stress level, all specimens have similar crack patterns. As seen in Fig. 8, undamaged concrete exhibits a rather sudden drop in stress. However, after the peak stress, frost-damaged concrete develops more expansion in the lateral direction and exhibits a gradual decrease in stress. This means that frost-damaged concrete is more ductile in failure than undamaged concrete. The ductility index (ratio of strain at $80 \%$ of peak stress in the softening branch to strain at peak stress) of all specimens analyzed in this study is shown in Fig. 12.

All phenomena observed in this analytical simulation have been confirmed in experiments (Hasan et al. 2002a; Hasan et al. 2003), which means that the model developed here is well able to simulate the fracture process of frost-damaged concrete.

Figure 13 shows the number of mortar and interface boundaries reaching a crack width of $0.03 \mathrm{~mm}$ due to compression loading in both undamaged and frost-damaged concrete. In both cases, the number shows a clear increase after the macro strain reaches a value slightly below 0.002, around which the peak stress is reached. This may imply that the number of boundaries with meso-scale cracks of width $0.03 \mathrm{~mm}$ can be treated as an index of the fracturing process in 
compression. In fact, Fig. 8 shows that strain at peak stress is rather similar among undamaged and frost-damaged concrete specimens, despite the fact that the peak stress decreases with increase in meso-scale plastic strain. The number of boundaries with a meso-scale crack measuring $0.03 \mathrm{~mm}$ in width increases in a rather similar manner among undamaged and frost-damaged concrete, although the frost-damaged concrete is more ductile after peak stress.

\section{Tension analysis}

Pure tension analysis was conducted on the same specimens as used in the compression analysis (see Fig. 7). The same meso-scale plastic tensile strain as in the compression analysis was used. The stress-strain curves obtained with the analytical model are shown in Fig. 14. Because there were no experimental tensile stress-strain curves available for frost-damaged concrete, no comparison can be made. From Fig. 14, however, it is clear that tensile strength and stiffness decrease with increasing frost damage. Strain at peak stress and ductility in softening increase as frost damage increases.

\section{Strength-stiffness relationship in compression and tension}

To compare the relationships between loss of strength and stiffness in compression and tension as well as the relationship between loss of compressive and tensile strength in frost-damaged concrete, analysis of specimens with meso-scale plastic tensile strains of $50 \mu$, $100 \mu, 500 \mu, 1000 \mu$, and $2500 \mu$ was also carried out in addition to the analysis described 
above. The relationships between loss of compressive stiffness and compressive strength, loss of tensile stiffness and tensile strength, and loss of compressive strength and tensile strength are shown in Figs. 15, 16 and 17, respectively. In each figure, the analytical results are compared with the previous experimental results (Hasan et al. 2002a; Hasan et al. 2002b; Hasan et al. 2003; Hasan et al. 2004; Matsumura et al. 2003). The good correlations further prove the validity of this meso-scale model for predicting the macro-scale behavior of frost-damaged concrete. The difference in compression and tension behavior of frost-damaged concrete as found in experiments (Hasan et al. 2002b; Hasan et al. 2003; Fagerlund 2002) was clearly predicted. Loss of tensile stiffness is somewhat proportional to loss of tensile strength (see Fig. 16). However, when the degree of frost damage is high, there is greater loss of compressive stiffness than of compressive strength (see Fig. 15). Furthermore, as found in the experiments, the loss of tensile strength is higher than that of compressive strength (see Fig. 17).

\section{Bending analysis}

Bending analysis on notched beam specimens of frost-damaged concrete was carried out for three cases of meso-scale plastic tensile strain: 0 (undamaged), $340 \mu$ (moderate damage), and $2000 \mu$ (serious damage). These values of meso-scale plastic tensile strain were chosen to give the same relative dynamic elastic modulus as in the experimental studies carried out by Hasan et al. (2002b) and Hasan (2003). All specimens have dimensions 400 mm x 100 mm with a notch 
$50 \mathrm{~mm}$ deep at the center. Each specimen is divided into 5200 polyhedron elements, as shown in Fig. 18. The specimen is supported by two simple supports and loaded at the center under displacement control.

The load deflection curves obtained in this analysis are compared with those obtained in the experimental studies (Hasan et al. 2002b; Hasan et al. 2003) in Fig. 19. It should be pointed out that, for convenience of comparison, the loads on both experimental and analytical load-deflection curves are normalized by their corresponding maximum values at the peak point. It is observed that there is good agreement of the normalized load-deflection curves between analytical and experimental results except in the softening branch of the specimen with $\varepsilon_{p f}=$ $2000 \mu$, confirming the applicability of the proposed model for predicting the observed experimental trends. The analysis well simulates loss of both carrying capacity and stiffness due to frost damage, as found in the experiments. The experimental finding that the softening behavior of frost-damaged concrete is more ductile than that of undamaged concrete is simulated reasonably well. However, at high levels of frost damage, the analytical result predicts a more brittle behavior than the experimental result. This may be attributed to the increase of $w_{\max }$ induced by frost-damage as shown in Fig. 6, but we did not take it into account in the present model.

Macro cracking initiates at the notch when the maximum load is reached. After the crack 
starts, the load gradually decreases with increasing crack width and the crack propagates to the top face of the specimen. The cracking pattern at the point when the maximum crack width reaches the stress-free condition is shown in Fig. 20 for all analyzed models. The single crack that occurs in undamaged and moderately damaged concrete, as found in the experiments (Hasan et al. 2002b; Hasan et al. 2003), is simulated well. For highly damaged concrete, besides the main crack, a second crack also propagates through the specimen. This behavior was also observed in the experiment, where some small cracks also propagated around the main crack.

\section{Conclusions}

Meso-scale analysis of frost-damaged concrete using a two-dimensional rigid body spring model

(RBSM) was carried out. The following conclusions are drawn from this research:

1. Based on experimentally observed tensile plastic strains and cracks during freeze-thaw cycles, meso-scale plastic tensile strain and zero strength elements were introduced to represent the plasticity and fractures caused by frost action. The meso-scale plastic tensile strain, which is introduced as a pre-existing elongation of the normal spring, reduces the spring initial stiffness in compression and its peak stress in tension (see Fig. 6).

2. The macro-scale stress-strain curves of frost-damaged concrete can be predicted using the model. Prediction curves in compression before the peak stress are similar to those obtained 
in experiments. The analysis also well simulates the difference in loss of strength and stiffness in tension and compression as observed in experiments. The relationships between loss of compressive stiffness and strength, loss of tensile strength and stiffness, and loss of tensile and compressive strength obtained in the analysis agree well with experimental values.

3. The crack pattern in frost-damaged concrete specimens in the analysis is very similar to that of undamaged concrete before peak stress. After peak stress, the crack propagation mode of frost-damaged concrete diverges from that of undamaged concrete. Undamaged concrete exhibits a rather sudden fall in stress and suffers brittle failure, while frost-damaged concrete undergoes more expansion in the lateral direction without showing a sudden drop in stress after the peak stress.

4. The normalized load-deflection curves obtained from simulated bending tests on notched-beam specimens of undamaged and frost-damaged concrete are similar to those obtained in experiments, showing a reduction in peak load and in stiffness before the peak load and an increase in ductility after the peak load in the cased of damaged concrete. The simulation results in the propagation of a single crack in bending tests on undamaged and moderately-damaged concrete and of more than one crack in the case of highly-damaged concrete, in agreement with experimental observations. 


\section{Acknowledgment}

The authors acknowledge the financial support provided for this study by the Japan Society for the Promotion of Science (JSPS) and Grant-in-Aid for Scientific Research (A) (No.19206048), Japan. Also, partial financial support under the Center for Concrete Corea, Korea to the Yonsei University of Korea is gratefully acknowledged.

\section{References}

Asai, M., Terada, K., Ikeda, K, Suyama, H. and Fujii, K. (2003). “Meso-scopic numerical analysis of concrete structures by a modified lattice model.” J. Struct. Mech. Earthquake Eng., JSCE, 731(I-63), 19-30.

Bazant, Z. P., Kaner, F. C., Cedolin, L., Gusatis, G. and Di Luzio, G. (2004). "Fracturing material models based on micromechanical concepts.” Proc. FraMCoS-5, ASCE, V. Li, ed., Vail, Colo., 83-89.

Fagerlund, G. (2002). "Mechanical damage and fatigue effects associated with freeze-thaw of

materials.” Proc. $2^{\text {nd }}$ Int. Workshop on Frost Resistance of Concrete, RILEM, M. J. Setzer, and H. -J. Keck, eds., 197-204.

Hasan, M. (2003). “Modeling of stress-strain relationships of concrete damaged by freezing and 
thawing cycles.” PhD dissertation, Hokkaido University, Sapporo, Japan.

Hasan, M., Nagai, K., Sato, Y. and Ueda, T. (2002a). "Stress-strain behavior in tension and compression of concrete damaged by freezing and thawing cycles.” Proc. $2^{\text {nd }}$ Int. Workshop on Frost Resistance of Concrete, RILEM, M. J. Setzer, and H. -J. Keck, eds., 197-204.

Hasan, M., Nagai, K., Sato, Y. and Ueda, T. (2002b). “Tensile stress-crack width model of plain concrete damaged by freezing and thawing action.” Proc. JCI, 24(2), 109-114.

Hasan, M., Okuyama, H. and Ueda, T. (2003). "The damage mechanism and strain induced in frost cycles of concrete.” Proc. JCI, 25(1), 401-406.

Hasan, M., Okuyama, H., Sato, Y. and Ueda, T. (2004). "Stress-strain model of concrete damaged by freezing and thawing cycles.” J. Adv. Concr. Tech., 2(1), 89-99.

Hsu, T.T.C. and Slate, F.O. (1963). “Tensile bond strength between aggregate and cement paste or mortar.” ACI J., 60(4), 465-485.

Jacobsen, S., Gran, H. C., Sellevold, E. J. and Bakke, J. A (1995). "High strength concrete-freeze/thaw testing and cracking.” Cem. Concr. Res, 25(8), 1775-1780.

JSCE (2005a). "Standard specification for concrete structures - 2002 'materials and construction' 6.2.5.3 Grading.” JSCE Guidelines for Concrete, Japan Society of Civil Engineers (JSCE), 6, 83.

JSCE (2005b). "Standard specifications for concrete structures - 2002 structural performance 
verification' 3.2.4 Tension softening properties.” JSCE Guidelines for Concrete, Japan Society of Civil Engineers (JSCE), 3, 31-32.

Kawai, T. (1977). "New element models in discrete structural analysis.” J. Society of Naval Architect of Japan, 141, 187-193.

Kawai, T. and Takeuchi, N. (1990). Discrete limit analysis program. Series of limit analyses by computer 2, Baifukan, Tokyo (in Japanese).

Kosaka, Y., Tanigawa, Y. and Kawakami, M. (1975). "Effect of coarse aggregate on fracture of concrete (part 1).” AIJ J., 228, 1-11 (in Japanese).

Matsumura, T., Katsura, O. and Yoshino, T. (2003). "Properties of frost damaged concrete and the estimation of the degree of frost damage.” J. Struct. Const. Eng., AIJ, 563(9-13), 9-13 (in Japanese).

Nagai, K., Sato, Y. and Ueda, T. (2004). "Mesoscopic simulation of failure of mortar and concrete by 2D RBSM.” J. Adv. Concr. Tech., 2(3), 359-374.

Nagai, K., Sato, Y. and Ueda, T. (2005). "Mesoscopic simulation of failure of mortar and concrete by 3D RBSM.” J. Adv. Concr. Tech., 3(3), 385-402.

Okabe, A., Boots, B., Sugihara, K. and Chiu, S.N. (2000). Spatial tessellations - Concepts and applications of voronoi diagrams, $2^{\text {nd }}$ ed., Wiley, New York.

Stroeven, P. and Stroeven, M. (2001). “Space approach to concrete’s space structures and its 
mechanical properties.” Heron, 46(4), 265-289.

Sugihara, K. (1998). Fortran computational geometry programming. Iwanami Shoten, Tokyo (in Japanese).

Taylor, M.A. and Brom, B.B. (1964). “Shear bond strength between coarse aggregate and cement paste or mortar.” ACI J., 61(8), 939-956.

Wittmann, F.H. (2004). “Crack formation and life cycle performance.” Proc. FraMCoS-5, ASCE, V. Li, ed., Vail, Colo., 3-10.

Yang, Z., Weiss, W. J. and Olek, J. (2006). "Water transport in concrete damaged by tensile loading and freeze-thaw cycling.” J. Mater. in Civil Eng., 18(3), 424-434.

Yoshimoto, A., Hasegawa, H. and Kawakami, M. (1983). “Comparison of strength obtained from pure tension, split and bending tests of concrete and mortar.” Cement Concrete, 435, 42-48 (in Japanese). 
Table 1. Input Material Properties

\begin{tabular}{cccc}
\hline Parameters & Mortar & Aggregate & Interface \\
\hline$f_{t}(\mathrm{MPa})$ & 4.09 & N.A. ${ }^{\mathrm{a}}$ & 1.83 \\
$E(\mathrm{GPa})$ & 25.0 & 50.0 & - \\
$v$ & 0.18 & 0.25 & - \\
$c(\mathrm{MPa})$ & - & - & 3.05 \\
$\phi\left(^{\circ}\right)$ & - & - & 35 \\
\hline
\end{tabular}

a) It is assumed that the aggregate does not fracture. 


\section{List of Figure Captions}

Fig. 1. Elements, springs and degrees of freedom

Fig. 2. Material constants at interface

Fig. 3. Constitutive relationship for normal spring in tension region; (a) Nagai's original model; (b) modified model used in this study

Fig. 4. Unloading-reloading path; (a) Nagai's original model, (b) modified model used in this study

Fig. 5. Distribution of meso-scale plastic tensile strain $\left(\varepsilon_{p}\right)$ and definition of zero strength elements

Fig. 6. Constitutive relationships for normal spring of frost damaged concrete

Fig. 7. Analyzed model of compression and tension

Fig. 8. Comparison between analytical and experimental stress-strain curves for concrete with different degrees of frost damage

Fig. 9. Comparison of strength and elastic modulus degradation between experiment and analysis

Fig. 10. Crack pattern at peak stress for five specimens with different degrees of frost damage

Fig. 11. Crack pattern at $80 \%$ of peak stress in softening branch for five specimens 
with different degrees of frost damage

Fig. 12. Relationship between ductility index and plastic strain

Fig. 13. Number of interfaces reaching a crack width of $0.03 \mathrm{~mm}$ in numerical analysis

Fig. 14. Analytical stress-strain curves under uniaxial tension with different damage levels

Fig. 15. Relationship between loss of compressive strength and stiffness

Fig. 16. Relationship between loss of tensile strength and stiffness

Fig. 17. Relationship between loss of compressive strength and tensile strength

Fig. 18. Simulated bending test model (in $\mathrm{mm}$ )

Fig. 19. Comparison of load-deflection curves between analysis and experiment for different levels of frost damage

Fig. 20. Crack pattern under bending with maximum crack width reaching stress-free condition 


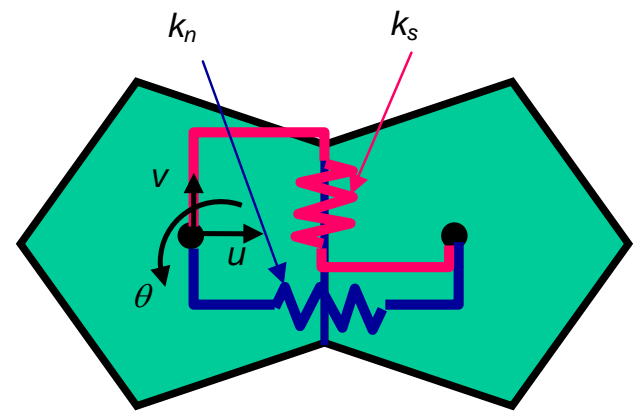

Fig. 1. Elements, springs and degrees of freedom 


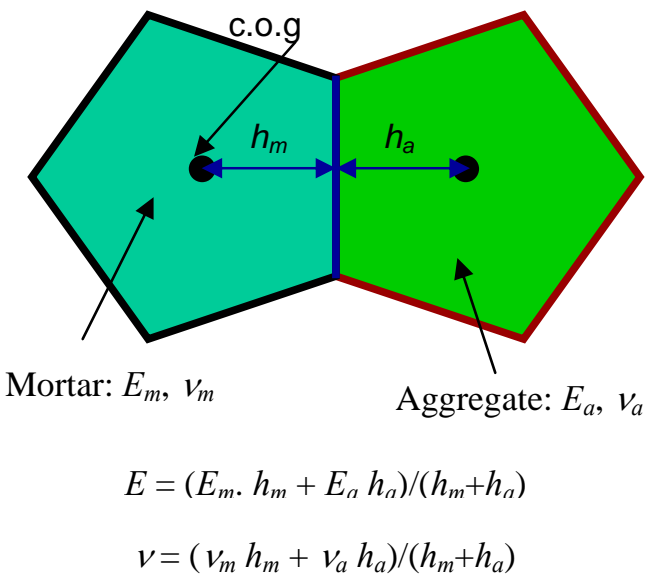

Fig. 2. Material constants at interface 

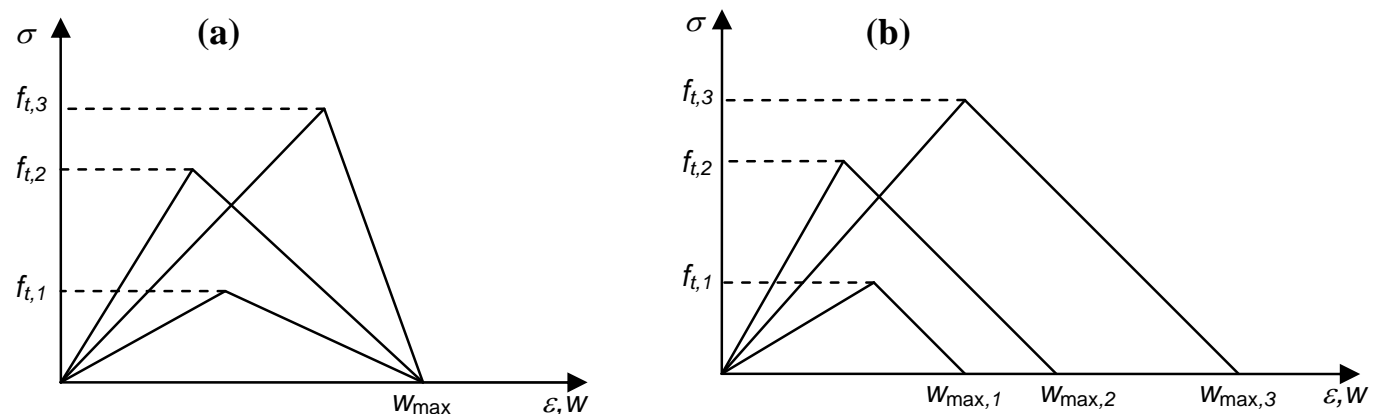

Fig. 3. Constitutive relationship for normal spring in tension region; (a) Nagai's original model; (b) modified model used in this study 

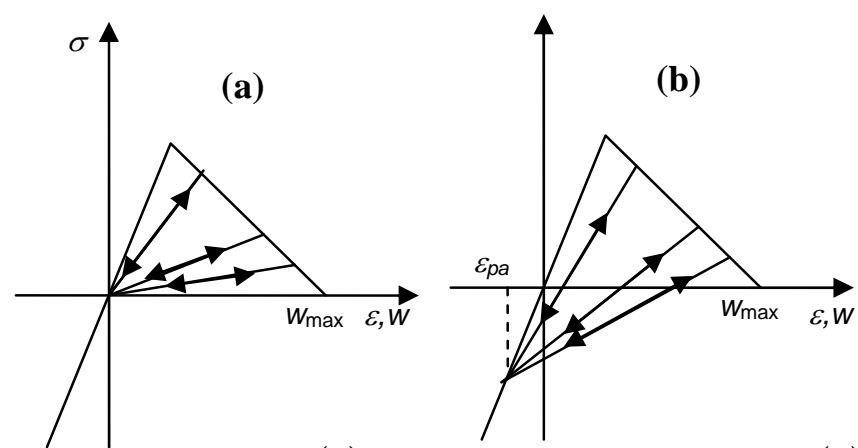

Fig. 4. Unloading-reloading path; (a) Nagai's original model, (b) modified model used in this study 


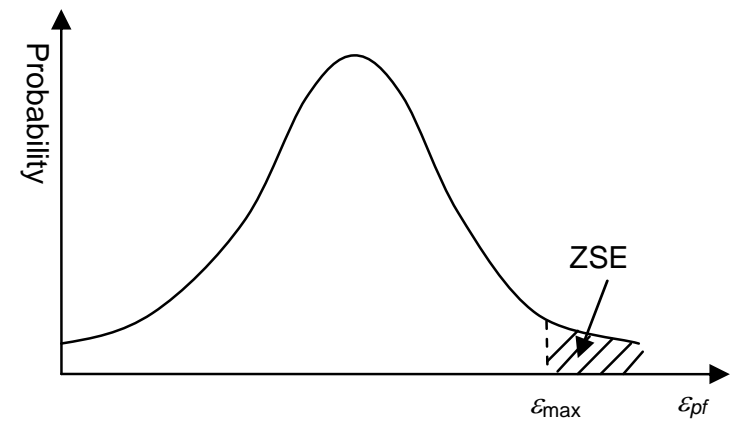

Fig. 5. Distribution of meso-scale plastic tensile strain $\left(\varepsilon_{p}\right)$ and definition of zero strength elements 


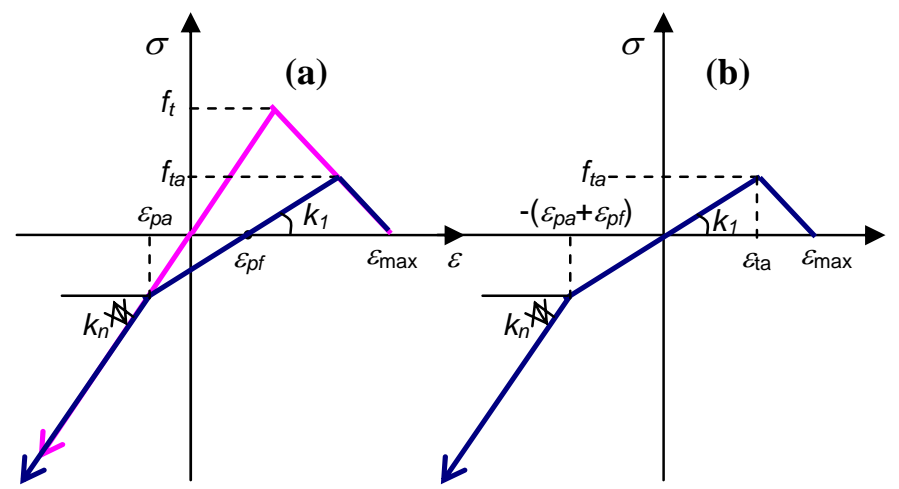

Fig. 6. Constitutive relationships for normal spring of frost damaged concrete 


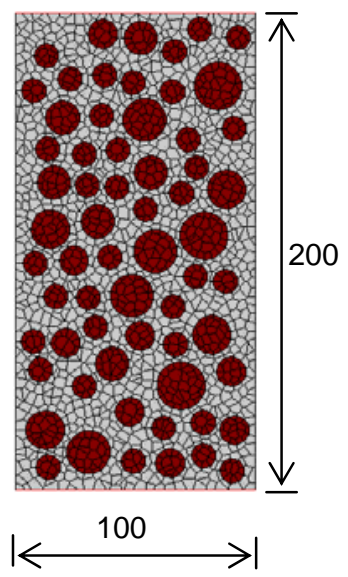

Fig. 7. Analyzed model of compression and tension 

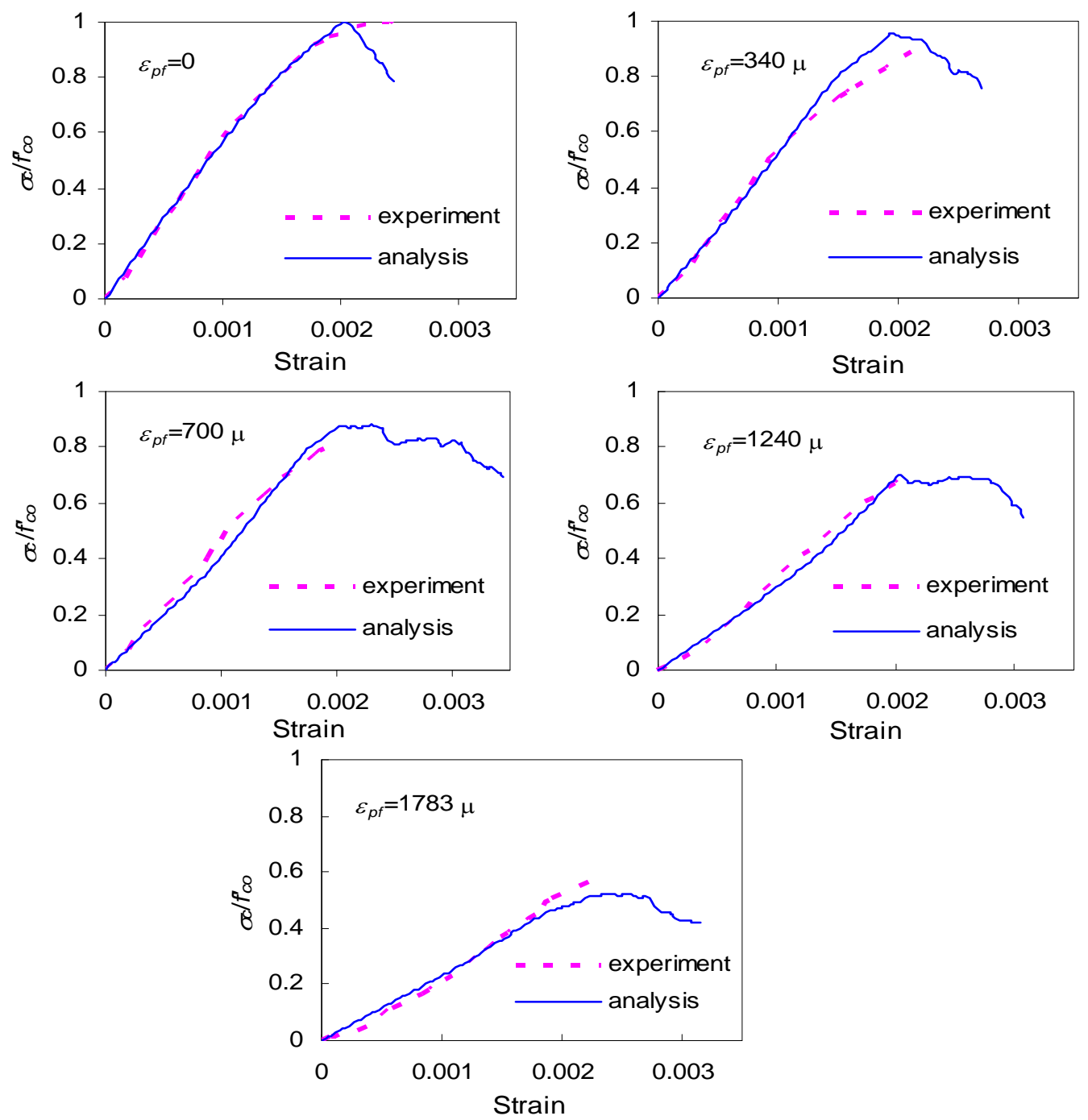

Fig. 8. Comparison between analytical and experimental stress-strain curves for concrete with different degrees of frost damage 


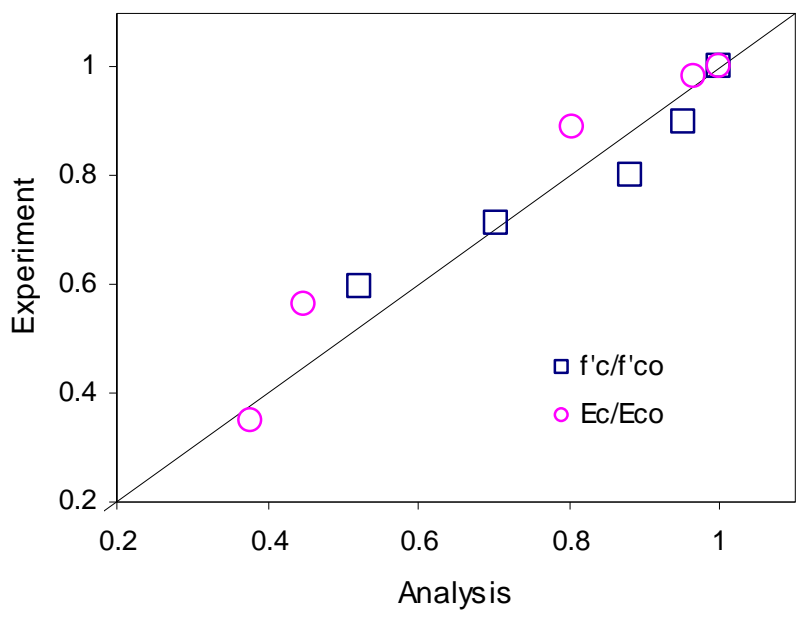

Fig. 9. Comparison of strength and elastic modulus degradation between experiment and analysis 


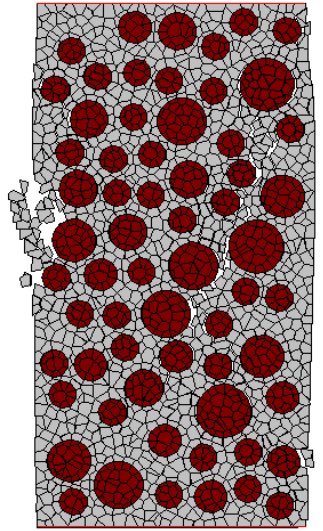

$\varepsilon_{p f}=0$

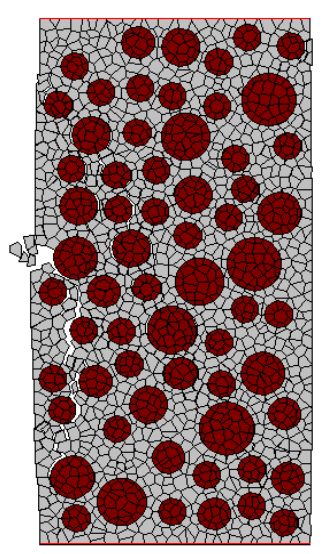

$\varepsilon_{p f}=340 \mu$

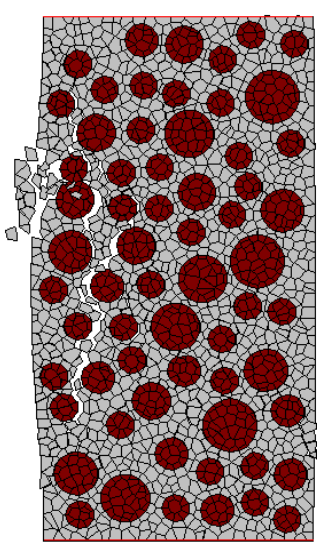

$\varepsilon_{p f}=700 \mu$

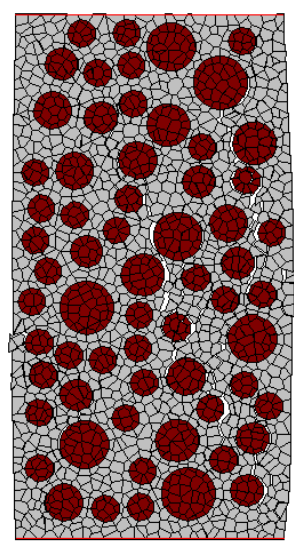

$\varepsilon_{p f}=1240 \mu$

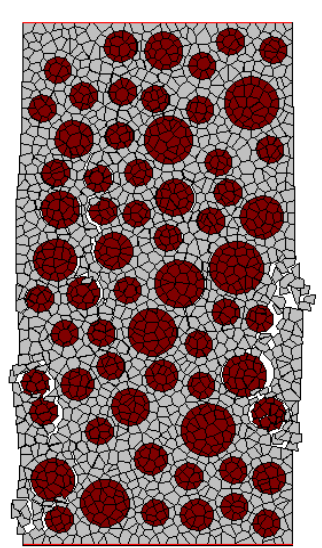

$\varepsilon_{p f}=1783 \mu$

Fig. 10. Crack pattern at peak stress for five specimens with different degrees of frost damage 


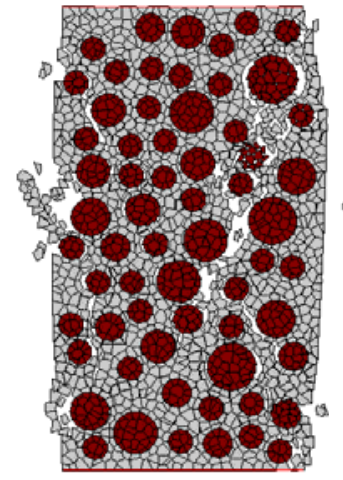

$\varepsilon_{p f}=0$

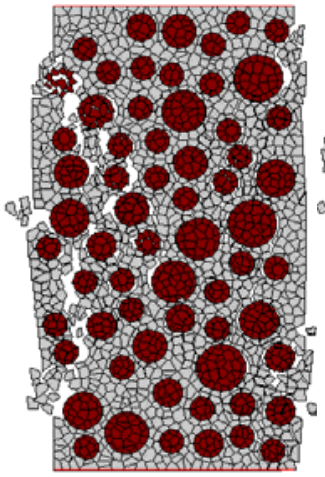

$\varepsilon_{p f}=340 \mu$

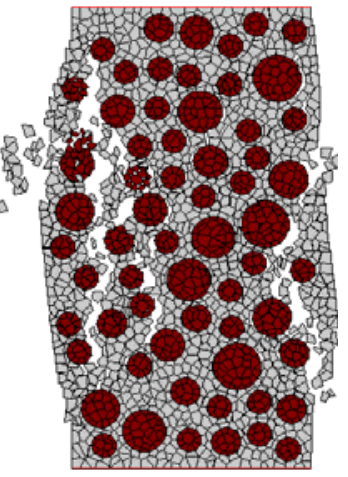

$\varepsilon_{p f}=700 \mu$

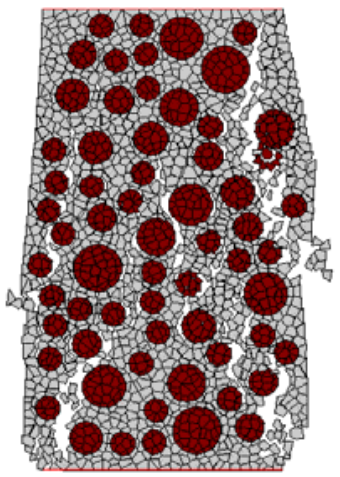

$\varepsilon_{p f}=1240 \mu$

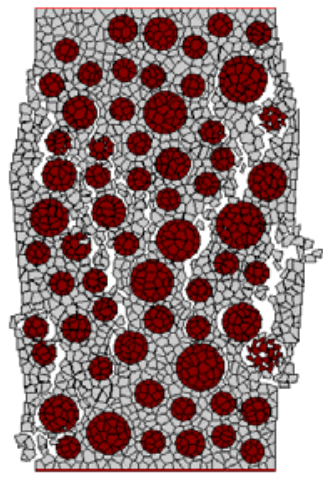

$\varepsilon_{p f}=1783 \mu$

Fig. 11. Crack pattern at $80 \%$ of peak stress in softening branch for five specimens with different degrees of frost damage 


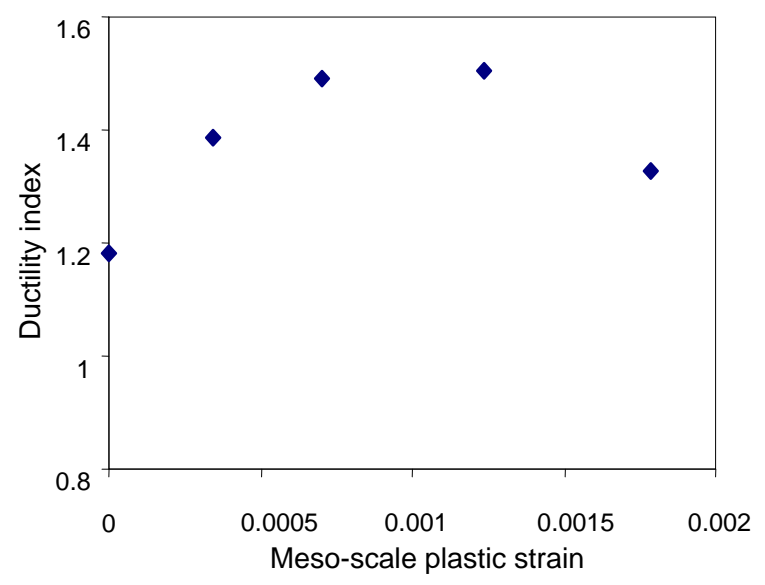

Fig. 12. Relationship between ductility index and plastic strain 

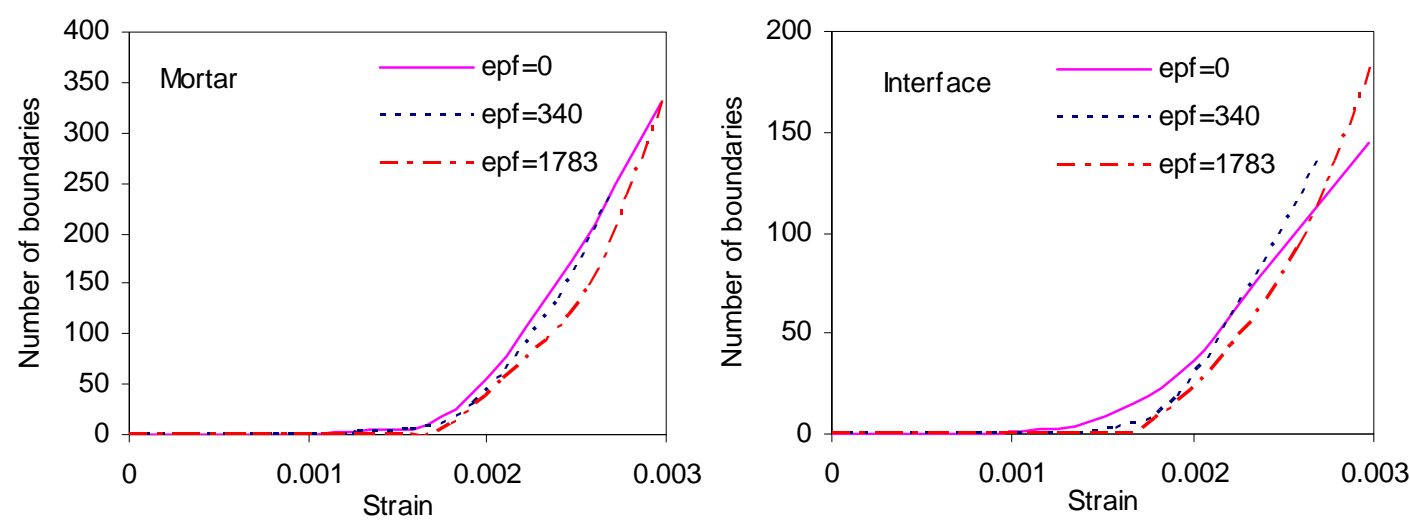

Fig. 13. Number of interfaces reaching a crack width of $0.03 \mathrm{~mm}$ in numerical analysis 


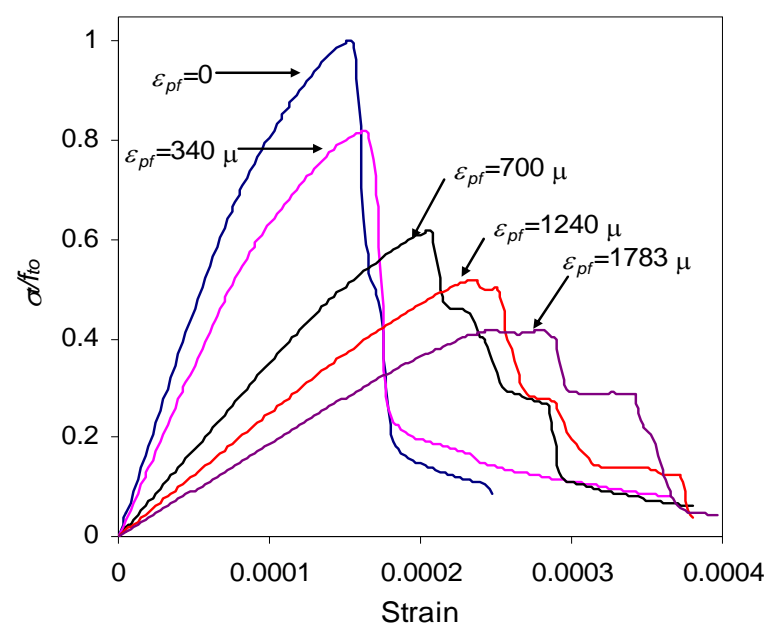

Fig. 14. Analytical stress-strain curves under uniaxial tension with different damage levels 


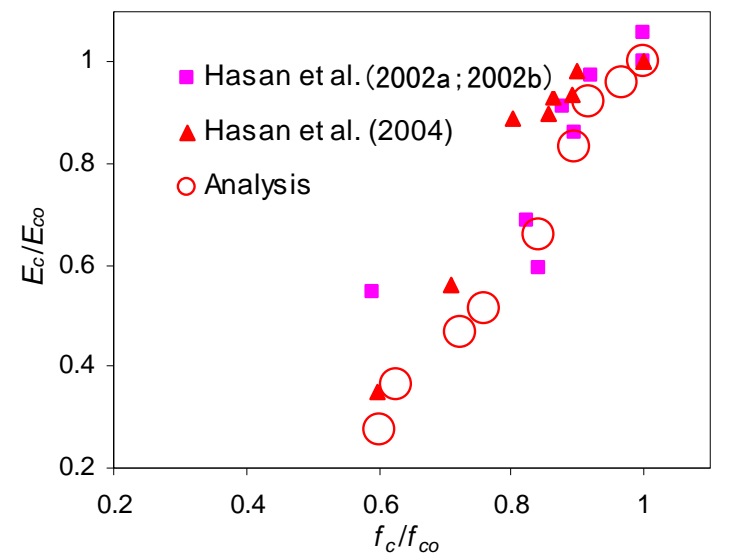

Fig. 15. Relationship between loss of compressive strength and stiffness 


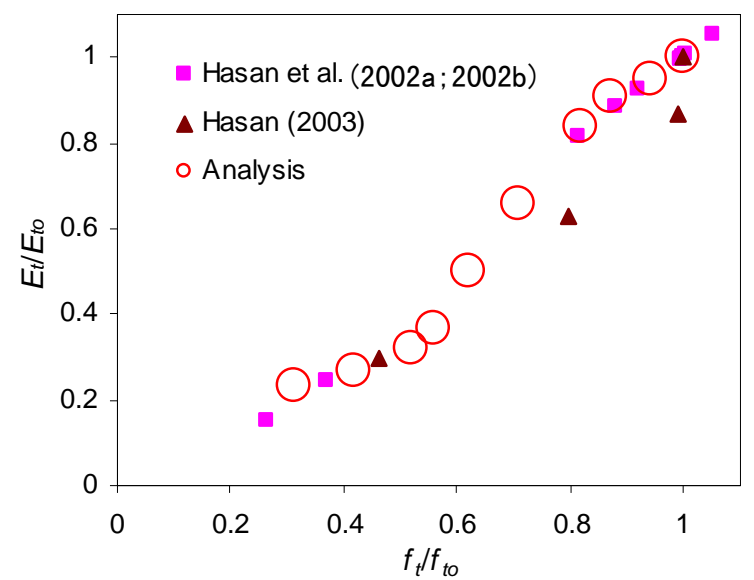

Fig. 16. Relationship between loss of tensile strength and stiffness 


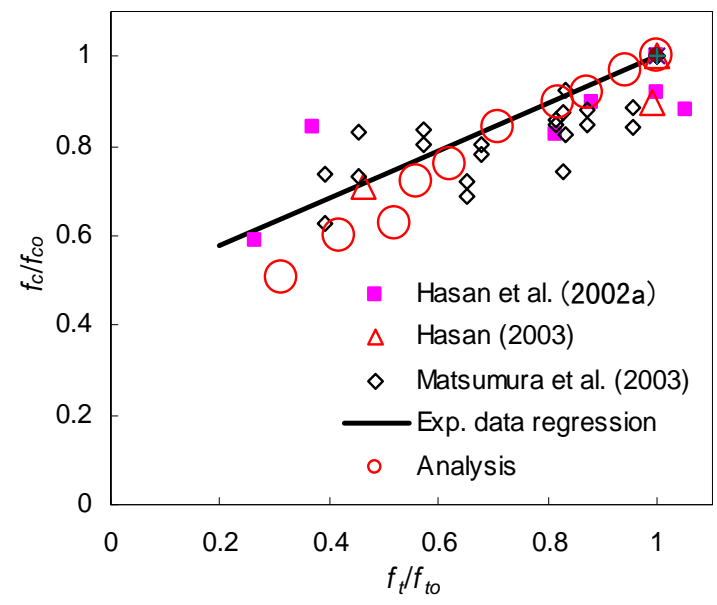

Fig. 17. Relationship between loss of compressive strength and tensile strength 


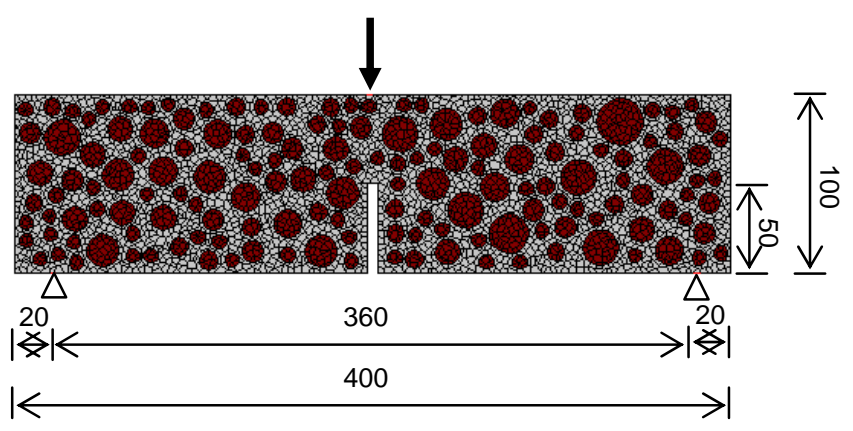

Fig. 18. Simulated bending test model (in $\mathrm{mm}$ ) 

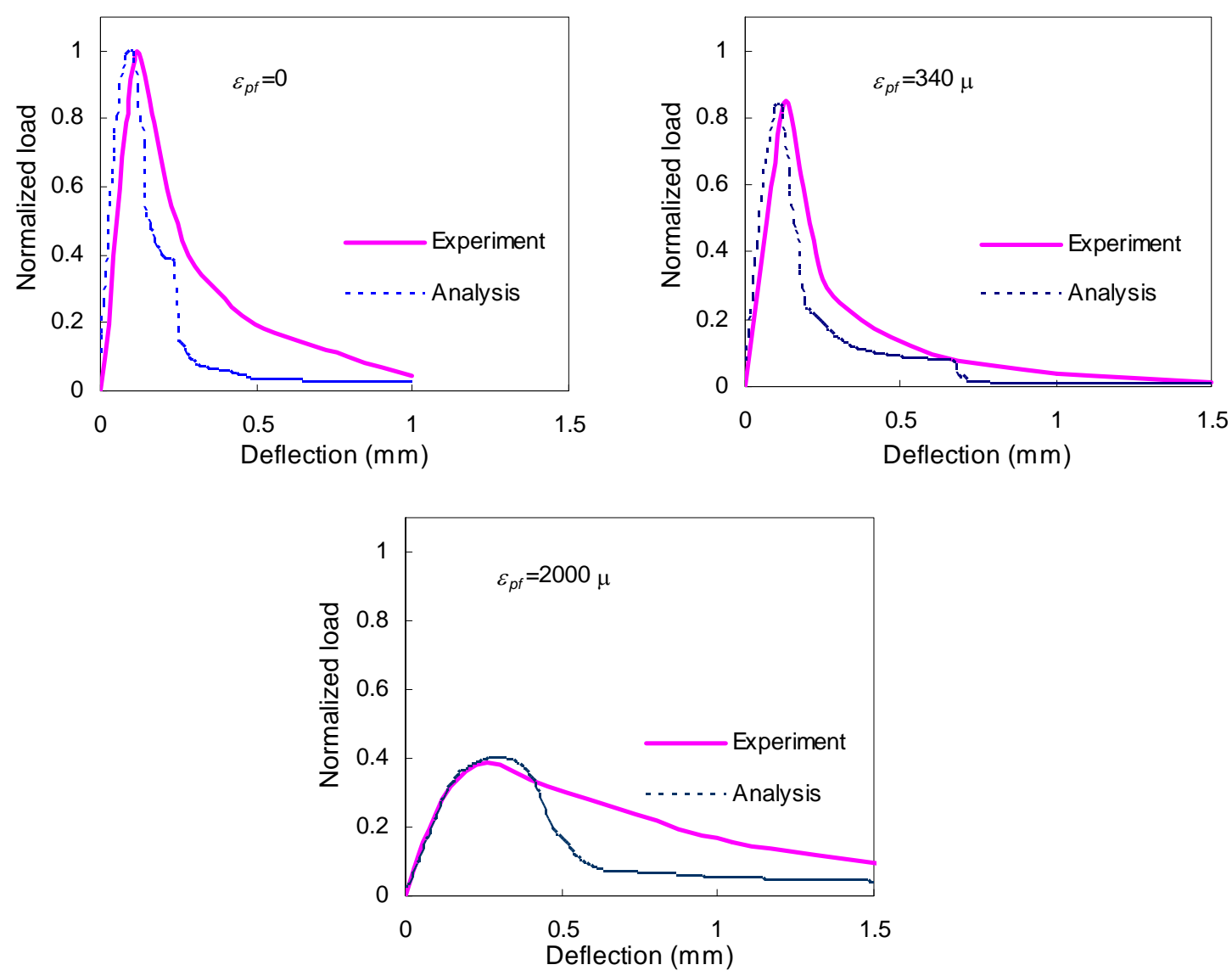

Fig. 19. Comparison of load-deflection curves between analysis and experiment for different levels of frost damage 

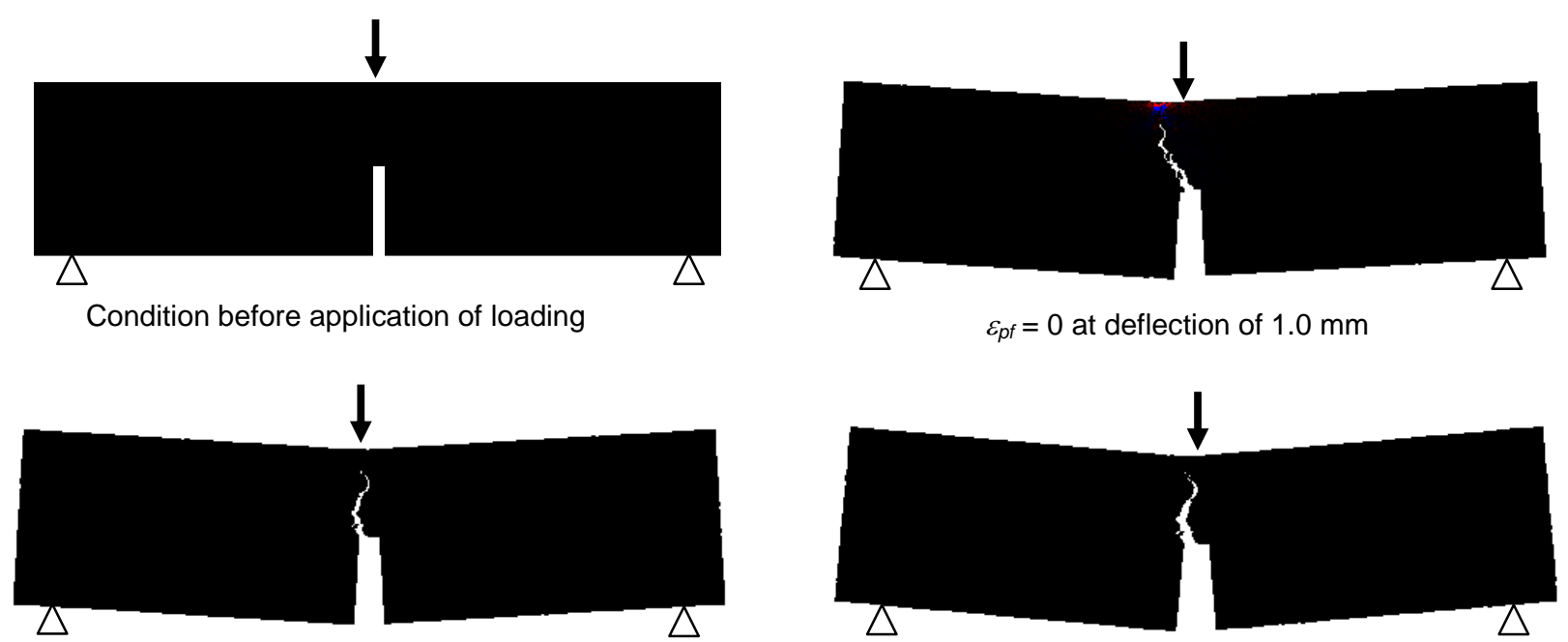

$\varepsilon_{p f}=340 \mu$ at deflection of $1.0 \mathrm{~mm}$

$\varepsilon_{p f}=340 \mu$ at deflection of $1.5 \mathrm{~mm}$

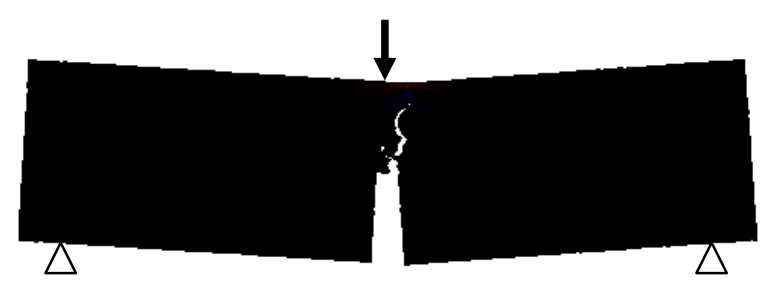

$\varepsilon_{p f}=2000 \mu$ at deflection of $1 \mathrm{~mm}$

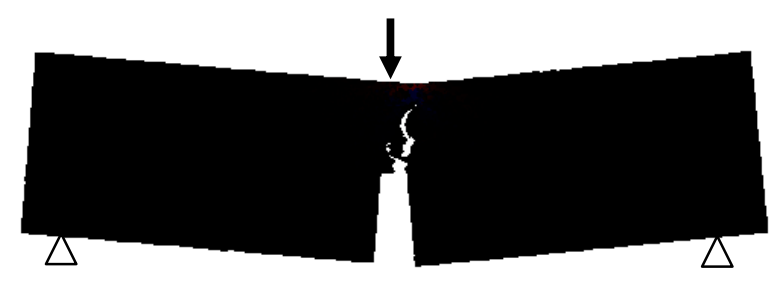

$\varepsilon_{p f}=2000 \mu$ at deflection of $1.5 \mathrm{~mm}$

Fig. 20. Crack pattern under bending with maximum crack width reaching stress-free condition 